\title{
Peak Stir Zone Temperatures during Friction Stir Processing
}

\author{
SRINIVASAN SWAMINATHAN, KEIICHIRO OH-ISHI, ALEXANDER P. ZHILYAEV, \\ CHRISTIAN B. FULLER, BLAIR LONDON, MURRAY W. MAHONEY, \\ and TERRY R. MCNELLEY
}

\begin{abstract}
The stir zone (SZ) temperature cycle was measured during the friction stir processing (FSP) of NiAl bronze plates. The FSP was conducted using a tool design with a smooth concave shoulder and a $12.7-\mathrm{mm}$ step-spiral pin. Temperature sensing was accomplished using sheathed thermocouples embedded in the tool path within the plates, while simultaneous optical pyrometry measurements of surface temperatures were also obtained. Peak SZ temperatures were $990{ }^{\circ} \mathrm{C}$ to $1015{ }^{\circ} \mathrm{C}\left(0.90\right.$ to $\left.0.97 T_{\text {Melt }}\right)$ and were not affected by preheating to $400{ }^{\circ} \mathrm{C}$, although the dwell time above $900{ }^{\circ} \mathrm{C}$ was increased by the preheating. Thermocouple data suggested little variation in peak temperature across the SZ, although thermocouples initially located on the advancing sides and at the centerlines of the tool traverses were displaced to the retreating sides, precluding direct assessment of the temperature variation across the SZ. Microstructure-based estimates of local peak SZ temperatures have been made on these and on other similarly processed materials. Altogether, the peak-temperature determinations from these different measurement techniques are in close agreement.
\end{abstract}

\section{INTRODUCTION}

FRICTION stir processing (FSP) and friction stir welding (FSW) are allied technologies involving localized severe plastic deformation induced by the action of a nonconsumable tool on a deformable material. In both FSP and FSW, the tool generally consists of a cylindrical shoulder portion with a projecting, concentric, and smaller-diameter pin. The tool is rotated while the pin is forced into the surface of the workpiece material. A combination of frictional and adiabatic heating leads to softening and allows the tool to penetrate until the shoulder comes into contact with the surface of the workpiece. Welding may be accomplished by traversing the tool along abutting edges of the restrained materials that are to be joined, so that metal flow around the pin leads to coalescence and the formation of a solid-state bond between similar or

SRINIVASAN SWAMINATHAN, Research Scientist, is with General Electric-Global Research, Bangalore 560066, India. KEIICHIRO OH-ISHI, Postdoctoral Scientist, is with the National Institute for Materials Science, Tsukuba, Ibaraki 305-0047, Japan. ALEXANDER P. ZHILYAEV, RyC Fellow, is with the Centro Nacional de Investigaciones Metalúrgicas (CENIM), CSIC, 28040 Madrid, Spain, and Leading Research Scientist, with the Institute for Metals Superplasticity Problems, RAS, 450001 Ufa, Russia. CHRISTIAN B. FULLER, Research Engineer, is with General Electric Co., Healthcare Division, Milwaukee, WI, 53219. BLAIR LONDON, Professor, is with the Department of Materials Engineering, California Polytechnic State University, San Luis Obispo, CA 93407. MURRAY W. MAHONEY is Independent Consultant, Midway, UT 84049. TERRY R. MCNELLEY, Distinguished Professor, is with the Center for Materials Science and Engineering, Department of Mechanical and Astronautical Engineering, Naval Post Graduate School, Monterey, CA 93943-5146. Contact e-mail: tmcnelley@nps.edu dissimilar materials. ${ }^{[1]}$ In FSP, the tool may be traversed in a predetermined pattern to process a volume in the workpiece defined by the pin tool profile and the traversing pattern. When applied to a cast metal, FSP may convert the as-cast stir zone (SZ) microstructure to a wrought condition, thereby improving physical and mechanical properties in the absence of a macroscopic shape change. ${ }^{[2,3]}$

Heating during FSP/FSW is due to a combination of adiabatic deformation in a volume of material surrounding the tool pin and friction at the workpiece-tool interface. The equilibrium of forces and moments, traversing of the tool, and localized plastic deformation induced by tool rotation result in rapid transients and steep gradients in the SZ strain, strain rate, and temperature. The extent of the SZ and surrounding thermomechanically affected zone (TMAZ) depends on the constitutive behavior of the material as well as the tool design and processing conditions. Tool features such as threads, flutes, or stepped spirals result in complex SZ deformation fields that lead to further difficulty in evaluation of the strain, strain rate, and temperature distributions. For example, from thermocouples placed outside of SZs ${ }^{[4,5]}$ and computational modeling, ${ }^{[6,7]}$ peak SZ temperatures have been estimated to be 0.6 to 0.8 $T_{\text {Melt }}$ during the FSP/FSW of various metals and alloys. In contrast, from the quantitative analysis of SZ microstructural constituents, the peak temperatures have been estimated to be $\geq 0.9 T_{\text {Melt }}$ during the FSP of NiAl bronze. ${ }^{[8-11]}$ This discrepancy has motivated the present investigation to measure the SZ temperature by placement of thermocouples directly in the tool path as well as by the use of optical pyrometry, and then to compare the results to microstructure-based estimates for NiAl bronze materials subjected to FSP. 
Table I. Composition (Weight Percent) Data for NiAl Bronze ${ }^{[28]}$

\begin{tabular}{|c|c|c|c|c|c|c|c|}
\hline Element & $\mathrm{Cu}$ & $\mathrm{Al}$ & $\mathrm{Ni}$ & $\mathrm{Fe}$ & $\mathrm{Mn}$ & $\mathrm{Si}$ & $\mathrm{Pb}$ \\
\hline Minimum/maximum & $79.0(\min )$ & 8.5 to 9.5 & 4.0 to 5.0 & 3.5 to 4.5 & 0.8 to 1.5 & $0.10(\max )$ & $0.03(\max )$ \\
\hline Nominal & 81 & 9 & 5 & 4 & 1 & - & - \\
\hline Typical plate & 81.2 & 9.39 & 4.29 & 3.67 & 1.20 & 0.05 & $<0.005$ \\
\hline
\end{tabular}

Microstructure-based estimates of the peak SZ temperature in the NiAl bronze rely on quantitative analysis of the alloy constituents, because they are affected by the FSP-induced thermomechanical history. ${ }^{[8-11]}$ The constitution and transformation characteristics of $\mathrm{NiAl}$ bronze materials have been described in detail elsewhere. ${ }^{[12-24]}$ An alloy with the nominal alloy composition listed in Table I solidifies at $\sim 1050{ }^{\circ} \mathrm{C}$ as a bcc $\beta$ phase. In large marine castings, near-equilibrium microstructures form during subsequent cooling at a rate that is typically $\sim 10^{-3}{ }^{\circ} \mathrm{C} / \mathrm{s}$. The primary fcc $\alpha$ solid solution then begins to form at $\sim 1000{ }^{\circ} \mathrm{C}$ with a Widmanstätten morphology in the $\beta$. At $930{ }^{\circ} \mathrm{C}$, a globular precipitate $\kappa_{\mathrm{ii}}$, which is $\mathrm{Fe}_{3} \mathrm{Al}$ having a $\mathrm{DO}_{3}$ structure, begins to form in the $\beta$, while a finer $\kappa_{\text {iv }}$ precipitate, which is also nominally $\mathrm{Fe}_{3} \mathrm{Al}$, forms in the primary $\alpha$, beginning at $\sim 860{ }^{\circ} \mathrm{C}$. The volume fraction of $\beta$ decreases until the eutectoid decomposition reaction $\beta \rightarrow \alpha+\kappa_{\mathrm{iii}}$ takes place over the temperature range $\sim 800{ }^{\circ} \mathrm{C}$ to $760{ }^{\circ} \mathrm{C}$. The $\kappa_{\mathrm{iii}}$ in the eutectoid constituent is nominally $\mathrm{NiAl}$ having a B2 structure, and typically exhibits a coarse lamellar morphology.

Reversion of the eutectoid constituent to form $\beta$ will begin upon reheating the slowly cooled material into the eutectoid range, and heating to higher temperatures of $800{ }^{\circ} \mathrm{C}$ to $1000{ }^{\circ} \mathrm{C}$ will result in an increasing volume fraction of $\beta$ as well as progressive dissolution of the $\kappa_{\mathrm{iv}}$ and $\kappa_{\mathrm{ii}}$ precipitates. The rates of these reactions are expected to be accelerated by a factor of up to $10^{4}$ in regions experiencing severe plastic deformation due to the generation of excess vacancies. ${ }^{[8,25-27]}$ Subsequent cooling at a rate characteristic of FSP $\left(\sim 10^{1}{ }^{\circ} \mathrm{C} \mathrm{s}^{-1}\right)$ results in the formation of nonequilibrium transformation products of the $\beta$ phase as well as retardation of the $\kappa_{\mathrm{iv}}$ and $\kappa_{\mathrm{ii}}$ reprecipitation. The nonequilibrium transformation products of $\beta$ may include fine Widmanstätten $\alpha$ as well as bainite and martensite, depending on the cooling rate. ${ }^{[8,9,14]}$ Therefore, quantitative analysis of the SZ and TMAZ microstructures enables prediction of the local peak temperatures if it is assumed that these microstructures approximately reflect equilibrium fractions of $\beta$ at peak temperature. Direct measurement by embedded thermocouples and optical pyrometry results will be compared to such microstructure-based estimates to assess peak SZ temperatures for selected FSP conditions applied to NiAl bronze materials.

\section{EXPERIMENTAL PROCEDURE}

The NiAl bronze plates of this study were sectioned from a large casting and machined to an approximate size of $300 \mathrm{~mm}$ in length $\times 150 \mathrm{~mm}$ in width $\times 19 \mathrm{~mm}$ in thickness; composition data are provided in Table I.

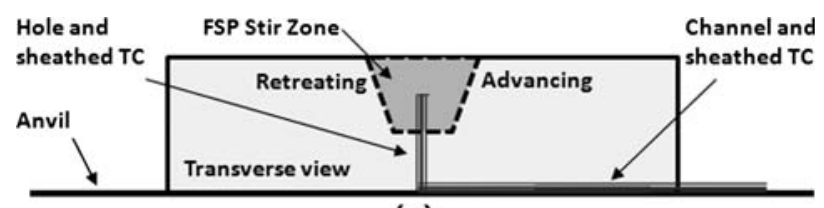

(a)

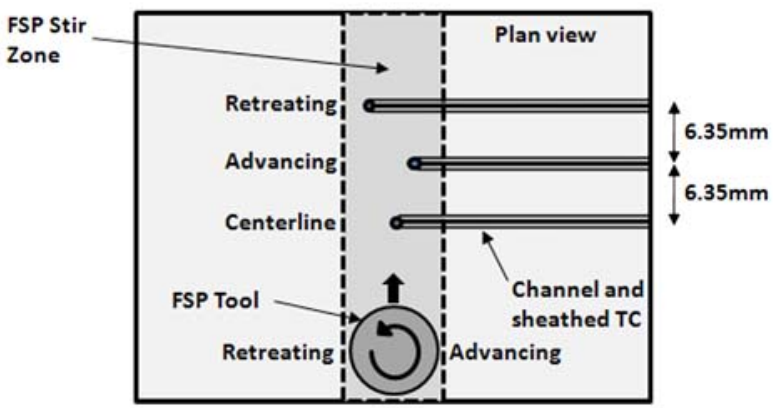

(b)

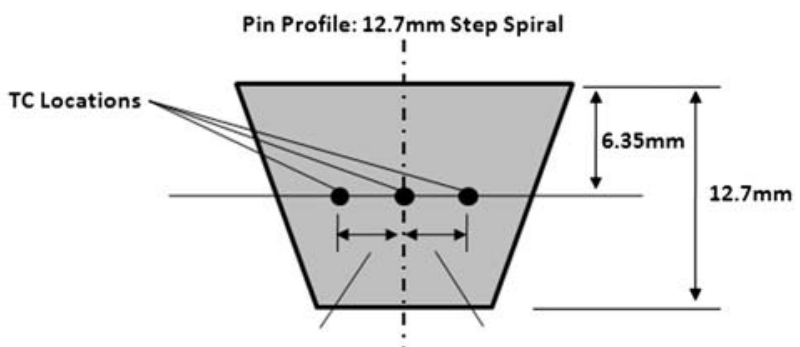

(c)

Fig. 1-Schematic diagrams illustrating the thermocouple locations: (a) transverse view of the plate cross section with the hole and channel for thermocouple placement, $(b)$ plan view of the plate showing the staggered arrangement of the thermocouples in the plane of the plate, and $(c)$ distribution of the thermocouples relative to the tool pin profile.

Direct thermocouple measurements were accomplished using sheathed and grounded type-K thermocouples $1.6 \mathrm{~mm}$ in diameter inserted into holes drilled at the bottom of the plate. Thermocouple placement is summarized in the schematics of Figure 1. The depth of the holes was chosen so that the thermocouple junctions would be located $6.35 \mathrm{~mm}$ below the top surface of the plate, i.e., at the mid-depth of the SZ, as shown in the schematic of Figure 1(a). One thermocouple was placed at the centerline while two others were offset by $2.9 \mathrm{~mm}$ to either side of the centerline in a staggered arrangement along the tool path, as shown in Figures 1(b) and (c). This placement was intended to allow assessment of the temperature variation across the SZ from the advancing side (the tangential velocity of a point on the tool surface adds to the traversing velocity) to the retreating side (the tangential velocity of a point on the 
tool surface subtracts from the traversing velocity). The drilled holes were small enough in diameter that the thermocouple sheaths were in contact with the side as well as the end of the hole. For sheathed and grounded type-K thermocouples embedded in a solid plate, an effective time constant can be estimated to be 0.02 to 0.06 seconds $^{[29]}$ and repeatability is estimated to be better than $1{ }^{\circ} \mathrm{C} .{ }^{[30]}$ Thermocouple output was recorded at 10 points per second using a computer-based data acquisition system. Finally, the thermocouple sheaths were bent around a radius and press fitted into a channel machined into the bottom of the plate; the channel edges were lightly peened to lock the thermocouples in place.

The effects of preheating the NiAl bronze on the FSP temperature cycle were investigated by heating a plate prior to processing. This was accomplished by placing an electrical resistance heater under the plate and covering it with a Fiberfrax* insulation blanket. The

*Fiberfrax is a registered trademark of Unifrax, Niagara Falls, NY.

temperature was monitored by the control thermocouple for the heater as well as the embedded measurement thermocouples. The FSP was conducted after equilibration at the preheating temperature of $400{ }^{\circ} \mathrm{C}$. The insulation was continuously moved to avoid excessive cooling from the preheating temperature.

The FSP was conducted using tools fabricated in Densimet 176 ** $^{*}$ The tools were machined to have a

\footnotetext{
**Densimet 176 is a registered trademark of Plansee Tungsten Alloys, Saint Pierre en Faucigny, France.
}

shoulder diameter of $28.6 \mathrm{~mm}$ and a pin in the shape of a truncated cone $12.7 \mathrm{~mm}$ in length with a base diameter of $15 \mathrm{~mm}$ and a tip diameter of $6.3 \mathrm{~mm}$. The pin also had a stepped spiral feature on the conical surface. The tool was always tilted $3 \mathrm{deg}$ away from the direction of the tool advance. The runs reported here involved a tool rotation rate of $1000 \mathrm{rpm}$ and the traversing rate was either $50.8 \mathrm{~mm} \mathrm{~min}^{-1}\left(2.0 \mathrm{in} . \mathrm{min}^{-1}\right)$ or $152.4 \mathrm{~mm}$ $\min ^{-1}\left(6.0\right.$ in. $\left.\min ^{-1}\right)$. The preheated material was processed at this same tool rotation rate and a traversing rate of $50.8 \mathrm{~mm} \mathrm{~min}^{-1}\left(2.0 \mathrm{in} . \mathrm{min}^{-1}\right)$. Surface temperature measurements were conducted on these plates and involved an optical pyrometer that was focused on the plate surface in which the heel of the tool shoulder was in contact with the plate. Care was taken to assure that "flash" from the processing did not interfere with the pyrometer measurement. The pyrometer (Wahl model DH552, Palmer Wahl Instrumentation Group, Asheville, NC) was calibrated using a black-body source in conjunction with a Hart Scientific model 9150 calibrator (Hart Scientific, American Fork, UT). The pyrometer was calibrated at a temperature of $950{ }^{\circ} \mathrm{C}$, based on values from the microstructure analysis. ${ }^{[8]}$ Repeatability was estimated to be $5^{\circ} \mathrm{C}$.

The volume fraction of the transformation products of FSP-induced $\beta, V_{\beta}$, was measured and used to obtain microstructure-based estimates of the peak SZ temperature following analysis procedures that have been given elsewhere. ${ }^{[8,9,11]}$ Briefly, preliminary experiments involving rapid cooling after either static annealing or isothermal hot rolling (with reheats of 10 minutes between successive passes) were conducted and the transformation products of $\beta$ were identified. The volume fraction of these transformation products $V_{\beta}$ was then determined by quantitative optical microscopy methods. For this purpose, samples were polished and then etched in a two-step process involving, first, immersion for 1 to 2 seconds in a solution of $40 \mathrm{~mL}$ water $+40 \mathrm{~mL}$ ammonium hydroxide $+2 \mathrm{~mL}$ hydrogen peroxide (30 pct) and rinsing in water, followed by immersion for 1 to 2 seconds in a solution of $60 \mathrm{~mL}$ water $+30 \mathrm{~mL}$ phosphoric acid $+10 \mathrm{~mL}$ hydrogen peroxide. Etched samples were examined using bright-field illumination in a Carl Zeiss Jenaphot 2000 (Carl Zeiss Jena GmbH, Jena, Germany) equipped with a digital imaging system, and $V_{\beta}$, which has an appearance quite distinct from the eutectoid $\alpha+\kappa_{\text {iii }}$ constituent, was determined by point counting on optical micrographs taken at a magnification of 370 times. Each $V_{\beta}$ measurement was repeated 4 times and the standard error of measurement was determined to be $0.1 V_{\beta}$ for $0<V_{\beta}<1$. Annealing times of 1 hour were found to result in equilibrium values of $V_{\beta}$ for temperatures varying from $760{ }^{\circ} \mathrm{C}$ to $1000{ }^{\circ} \mathrm{C}$. The results of these measurements can be summarized by the linear equation $T=244 V_{\beta}+758\left({ }^{\circ} \mathrm{C}\right)$ for $0 \leq V_{\beta} \leq 1$. This relationship has been applied to estimate SZ peak temperatures by the measurement of $V_{\beta}$ using the same point-counting method on optical micrographs from selected regions in the SZ. Here, the results of this analysis are presented as an average peak temperature at each measurement location as well as the range of values from four measurements. This approach assumes that the reversion of the eutectoid is accelerated by the generation of excess vacancies during severe plastic deformation, and the resulting microstructures represent near-equilibrium conditions for the temperature in question. ${ }^{[8,25-27]}$

\section{RESULTS}

\section{A. Thermocouple and Optical Pyrometer Measurements}

Thermal cycles are presented in Figure 2 for NiAl bronze materials subjected to FSP at $1000 \mathrm{rpm}$ and either 50.8 or $152.4 \mathrm{~mm} \mathrm{~min}^{-1}$ for plates initially at ambient temperature or at $1000 \mathrm{rpm}$ and $50.8 \mathrm{~mm} \mathrm{~min}^{-1}$ after preheating to $400{ }^{\circ} \mathrm{C}$. The plots in Figures 2(a), (c), and (e) show thermocouple output for the entire duration of the FSP experiment, while the plots in Figures 2(b), (d), and (f) show only that portion of the thermal cycle for $T \geq 700{ }^{\circ} \mathrm{C}$. In comparisons among the data in Figures 2(b), (d), and (f), the time scales are all different. Each graph in Figure 2 includes data for the three embedded thermocouples. The thermal cycles are offset along the time axis because of the staggered placement of the thermocouples (Figure 1). 


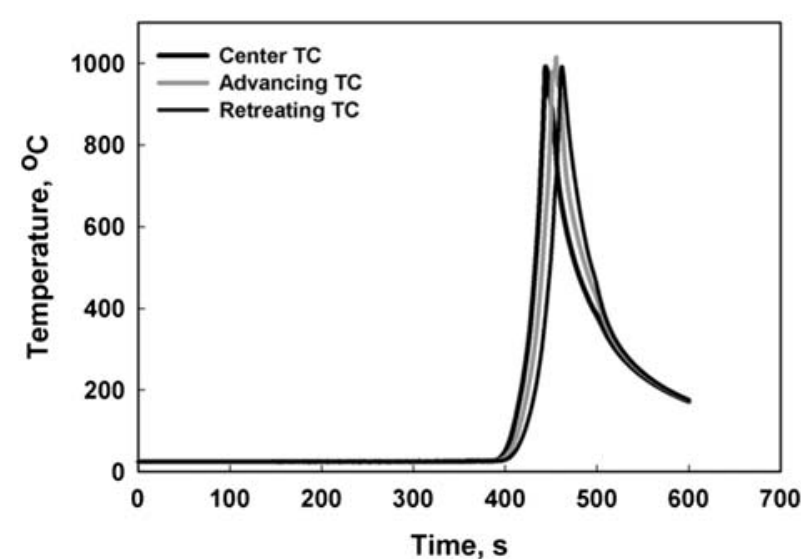

(a)

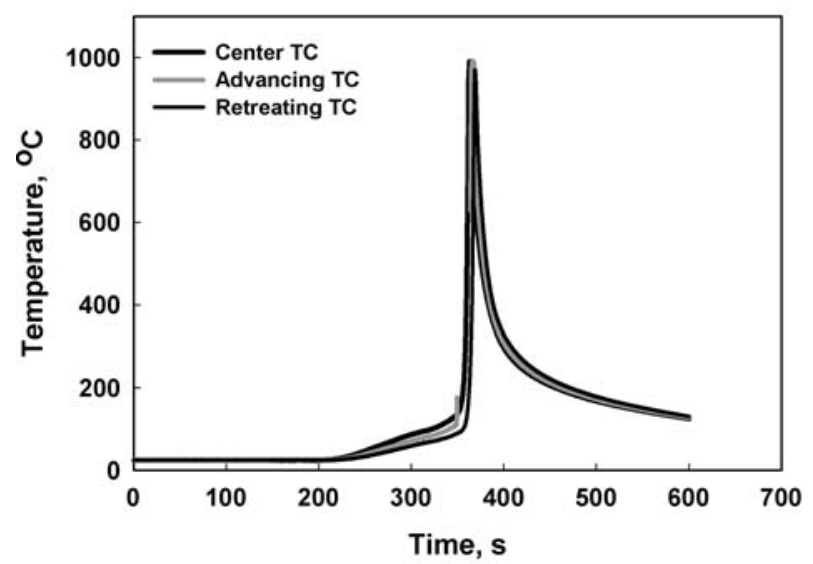

(c)

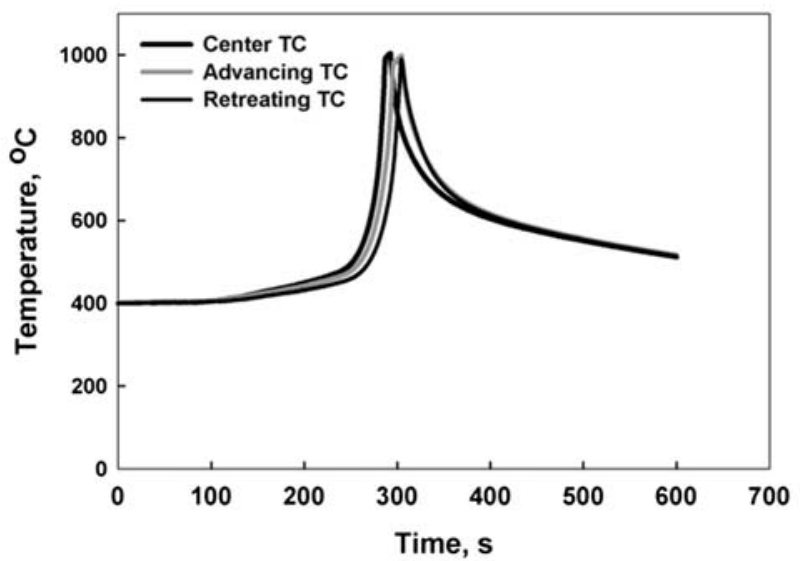

(e)

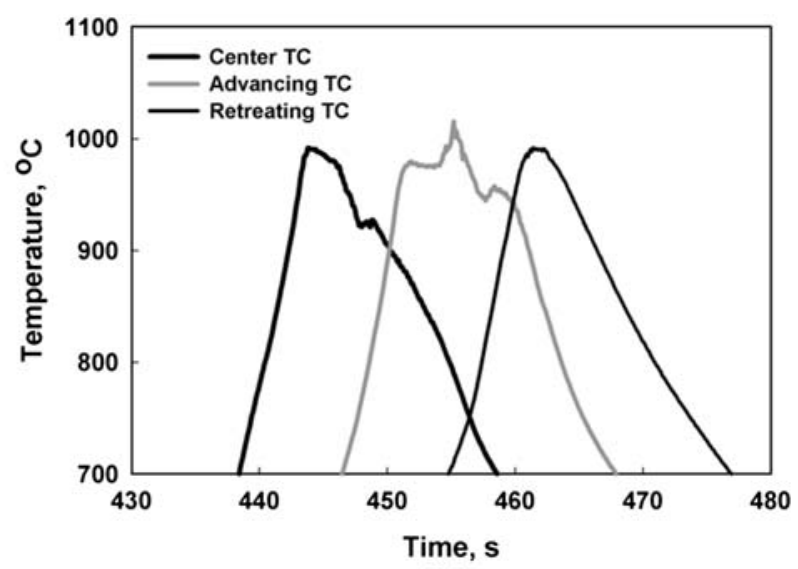

(b)

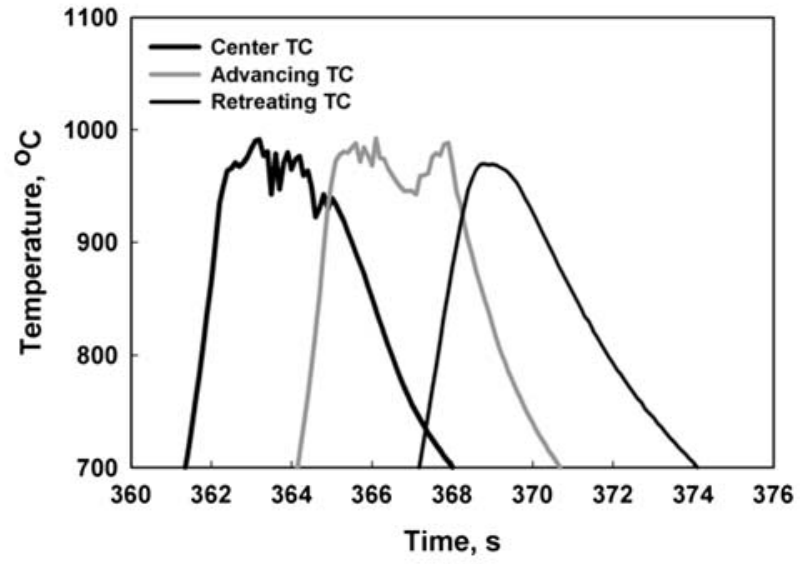

(d)

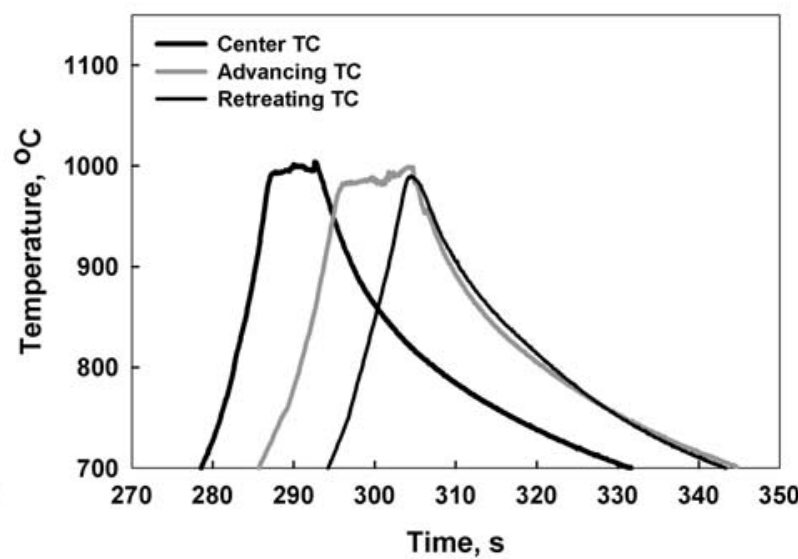

(f)

Fig. 2-Recorded thermal cycles for FSP runs with plates initially at ambient temperature and processing at $(a)$ and $(b) 1000 \mathrm{rpm}$ and $50.8 \mathrm{~mm}$ $\mathrm{min}^{-1}$ and $(c)$ and $(d) 1000 \mathrm{rpm}$ and $152.4 \mathrm{~mm} \mathrm{~min}^{-1}$. (e) and $(f)$ Thermal cycles for material preheated to $400{ }^{\circ} \mathrm{C}$ and processed at $1000 \mathrm{rpm}$ and $50.8 \mathrm{~mm} \mathrm{~min}^{-1}$. Complete thermal cycles are presented in $(a),(c)$, and $(e)$, while the portions of the thermal cycles above $700{ }^{\circ} \mathrm{C}$ are presented in $(b),(d)$, and $(f)$.

The centerline thermocouple is the first to be encountered by the tool, followed in succession by the advancing side and then the retreating side thermocouples. Thus, the offset along the time axis is the ratio of the distance between the thermocouples along the axis of the tool advance $(6.35 \mathrm{~mm})$ and the tool traversing rate, i.e., 7.5 seconds for traversing rates of $50.8 \mathrm{~mm} \mathrm{~min}^{-1}$ and 2.5 seconds for traversing at $152.4 \mathrm{~mm} \mathrm{m^{-1 }}$. Inspection of the individual temperature profiles in each of the Figures 2(b), (d), and (f) reveals such time offsets when the heating portions of the temperature profiles are compared. 
Table II. Thermocouple and Pyrometer Temperature Data

\begin{tabular}{|c|c|c|c|c|c|c|c|c|c|}
\hline \multirow{2}{*}{$\begin{array}{l}\text { FSP Condition } \\
\text { Thermocouple location }\end{array}$} & \multicolumn{3}{|c|}{$1000 / 50.8 / 25^{\circ} \mathrm{C}$} & \multicolumn{3}{|c|}{$1000 / 152.4 / 25^{\circ} \mathrm{C}$} & \multicolumn{3}{|c|}{$1000 / 50.8 / 400{ }^{\circ} \mathrm{C}$} \\
\hline & $\mathrm{Adv}^{*}$ & $\mathrm{Ctr} * *$ & $\operatorname{Ret}^{\dagger}$ & Adv & $\mathrm{Ctr}$ & Ret & Adv & $\mathrm{Ctr}$ & Ret \\
\hline$\partial T / \partial t$ heat $\left({ }^{\circ} \mathrm{C} / \mathrm{s}\right)$ & 58.1 & 46.8 & 68.0 & 287.0 & 261.6 & 210.6 & 28.9 & 37.2 & 29.3 \\
\hline$\partial T / \partial t \operatorname{cool}\left({ }^{\circ} \mathrm{C} / \mathrm{s}\right)$ & -34.4 & -29.4 & -19.5 & -100.2 & -93.8 & -56.8 & -5.7 & -6.2 & -6.8 \\
\hline$\Delta t_{700^{\circ} \mathrm{C}}(\mathrm{s})$ & 21.4 & 20.2 & 22.1 & 6.6 & 6.7 & 6.9 & 59.1 & 53.1 & 49.0 \\
\hline$\Delta t_{900^{\circ} \mathrm{C}}(\mathrm{s})$ & 10.9 & 7.9 & 7.3 & 3.6 & 3.4 & 2.23 & 15.8 & 12.0 & 8.7 \\
\hline$T_{\text {Peak }}\left({ }^{\circ} \mathrm{C}\right)$ & 1015.0 & 992.0 & 992.2 & 992.5 & 979.8 & 969.3 & 998.9 & 1003.9 & 990.0 \\
\hline$T_{\text {Peak,Pyrometer }}\left({ }^{\circ} \mathrm{C}\right)$ & \multicolumn{3}{|c|}{944 (surface) } & \multicolumn{3}{|c|}{970 (surface) } & \multicolumn{3}{|c|}{956 (surface) } \\
\hline $\begin{array}{l}\text { *Advancing side. } \\
* * \text { Centerline. } \\
{ }^{\dagger} \text { Retreating side. }\end{array}$ & & & & & & & & & \\
\hline
\end{tabular}

As the tool approaches the thermocouple locations, the thermal cycles in Figures 2(a), (c), and (e) exhibit heating at rates that depend on both the tool traversing rate and the plate preheating temperature. For each processing condition, the absolute heating rates are greater than subsequent cooling rates after the peak temperature is attained. These heating and cooling rates at $T=800{ }^{\circ} \mathrm{C}$ were determined from the digital thermocouple data and are summarized in Table II along with dwell times at temperatures above $700{ }^{\circ} \mathrm{C}$ and $900{ }^{\circ} \mathrm{C}$. Table II also includes peak temperatures for each thermocouple and optical pyrometer data. In the graphs of Figures 2(b), (d), and (f), the dwell time above $700{ }^{\circ} \mathrm{C}, \Delta t_{700^{\circ} \mathrm{C}}$, is largely unaffected by thermocouple placement, while the dwell time above $900{ }^{\circ} \mathrm{C}, \Delta t_{900}{ }^{\circ} \mathrm{C}$, increases in the progression from retreating to the centerline to the advancing side. This is evident in the temperature profiles of Figures 2(b), (d), and (f) as well as in Table II. Furthermore, the temperature profiles in Figures 2(b), (d), and (f) for the centerline and advancing side thermocouples exhibit temperature fluctuations in the vicinity of the peak temperature, while the retreating side profile is smooth around the peak temperature.

The foregoing observations together with the thermocouple placements illustrated in Figure 1 suggest that the centerline and advancing thermocouples are being displaced by direct interaction with the tool pin. Accordingly, grinding of the plates in the vicinity of the thermocouples was carried out, starting from the bottom sides of each plate, until the thermocouple tips were located. Examples are shown in Figure 3 for materials processed without preheating and at 1000

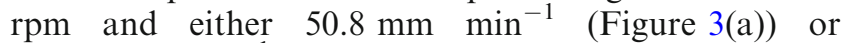
$152.4 \mathrm{~mm} \mathrm{~min}^{-1}$ (Figure 3(b)), and with preheating to $400{ }^{\circ} \mathrm{C}$ and at $1000 \mathrm{rpm}$ and $50.8 \mathrm{~mm} \mathrm{m^{-1 }}$ (Figure 3(c)). These images were obtained from a location either $12.4 \mathrm{~mm}$ (Figures 3(a) and (c)) or $11.9 \mathrm{~mm}$ (Figure 3(b)) below the top surfaces of these plates and thus correspond approximately to the bottom of the SZ. In all images, the SZ is apparent as a band of darker etching material extending from left to right. The SZ centerline and the tool traversing directions are indicated by the insets. In Figure 3, the centerline thermocouples have all been displaced toward the retreating side, although the tips of these thermocouples have not yet been revealed. The tips of the advancing side thermocouples are indicated in images in Figures 3(a) and (b) and their location suggests that these thermocouples have been displaced downward toward the bottom as well as toward the retreating side of the SZ. In contrast, the tip of the advancing side thermocouple appears to be located on the advancing side of the SZ in Figure 3(c), indicating that preheating may affect the SZ deformation field or thermocouple motion in this deformation field. In all cases, the retreating side thermocouples lie outside of the SZ and have not been affected by the tool at this depth below the plate surface.

The thermocouple data in this experiment indicate that preheating retards heating as well as cooling rates and increases dwell times but has little effect on the SZ peak temperature or its distribution. For materials processed at $1000 \mathrm{rpm}$ and $50.8 \mathrm{~mm} \mathrm{~min}{ }^{-1}$, the peak temperatures were $992{ }^{\circ} \mathrm{C}$ to $1015^{\circ} \mathrm{C}$ in the material processed without preheating and $990{ }^{\circ} \mathrm{C}$ to $1003{ }^{\circ} \mathrm{C}$ in the material preheated to $400{ }^{\circ} \mathrm{C}$. Likewise, pyrometer data suggest little effect of preheating; the surface temperature was $944{ }^{\circ} \mathrm{C}$ without preheating and $956{ }^{\circ} \mathrm{C}$ in the preheated material. However, processing without preheating at the higher traversing rate, $152.4 \mathrm{~mm} \mathrm{~min}^{-1}$, resulted in SZ peak temperatures of $969{ }^{\circ} \mathrm{C}$ to $992{ }^{\circ} \mathrm{C}$, i.e., values approximately $20{ }^{\circ} \mathrm{C}$ cooler at each thermocouple location. In contrast, pyrometry results indicate that the surface temperature was higher, $970{ }^{\circ} \mathrm{C}$, in material processed at the higher traversing rate when compared to the lower traversing rate. Altogether, the thermocouple and pyrometer measurements indicate that peak temperatures are 0.92 to $0.97 T_{\text {Melt }}$ for this NiAl bronze material.

\section{B. Microstructure-Based Estimates}

Transverse sections showing the SZ and surrounding material for the processing conditions of the present investigation are shown in Figure 4. The central SZ microstructure is highly refined in all cases and the grain structure cannot be resolved in these micrographs. An approximately circular "onion-ring" pattern, consisting of a combination of $\alpha$ and dark-etching $\beta$-transformation products, is apparent surrounding the central part of the SZ, although asymmetry of deformation due to the tool rotation is also apparent. The advancing side 


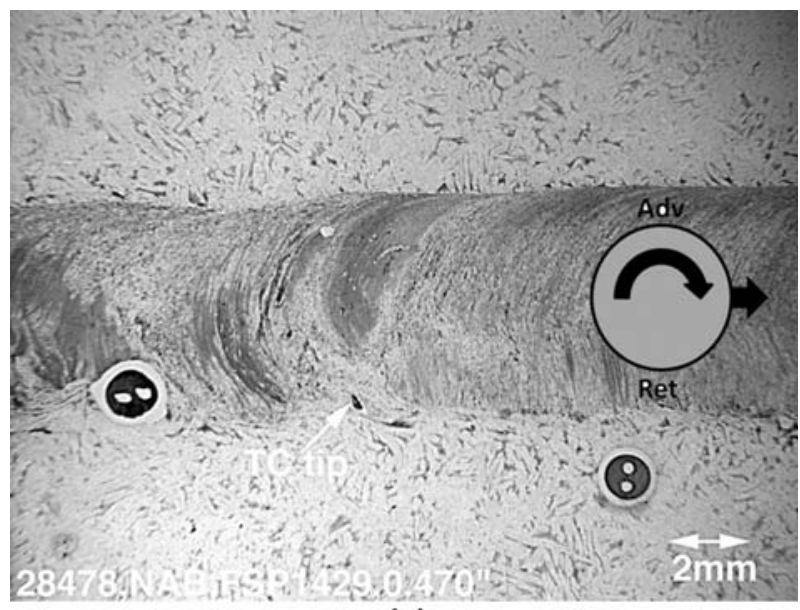

(a)

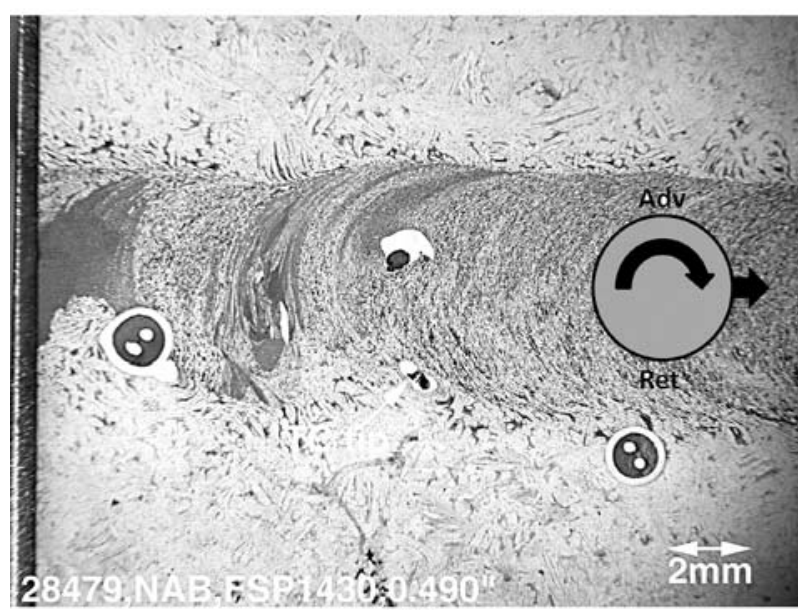

(b)

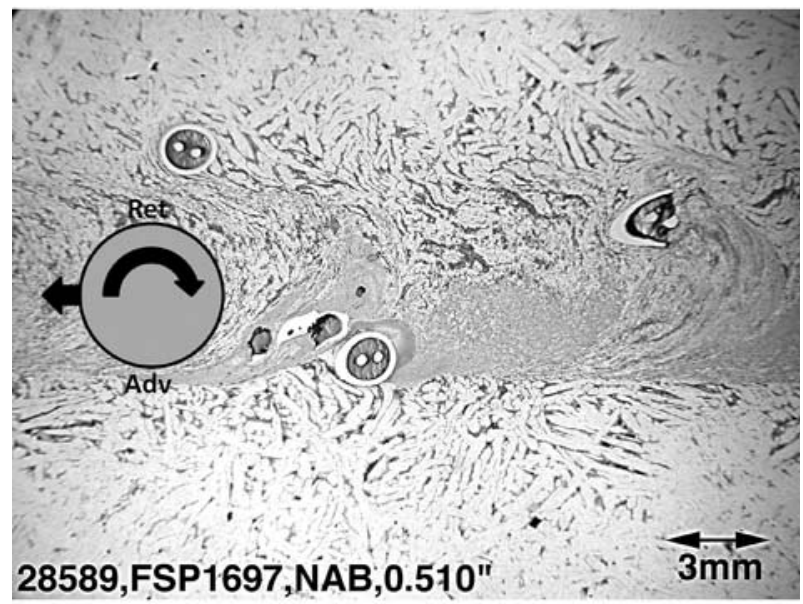

(c)

Fig. 3-Optical micrographs showing the bottom of the SZ in the plane of the plate and illustrating the displacement of thermocouples by the action of the tool pin during FSP. During the tool traverse, the thermocouples are encountered in the sequence centerline, advancing, retreating, i.e., $(a)$ and $(b)$ from left to right or $(c)$ from right to left. In $(a)$ and $(b)$, the centerline and advancing side thermocouples are displaced to the retreating side in materials initial at ambient temperature, and the advancing side thermocouple tip is also displaced to the bottom of the SZ. In $(c)$, the advancing side thermocouple remains on the advancing side of the SZ in material preheated to $400{ }^{\circ} \mathrm{C}$.

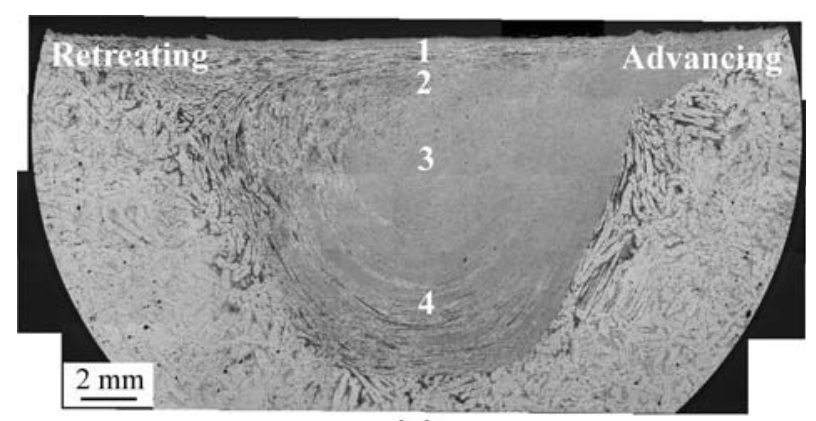

(a)

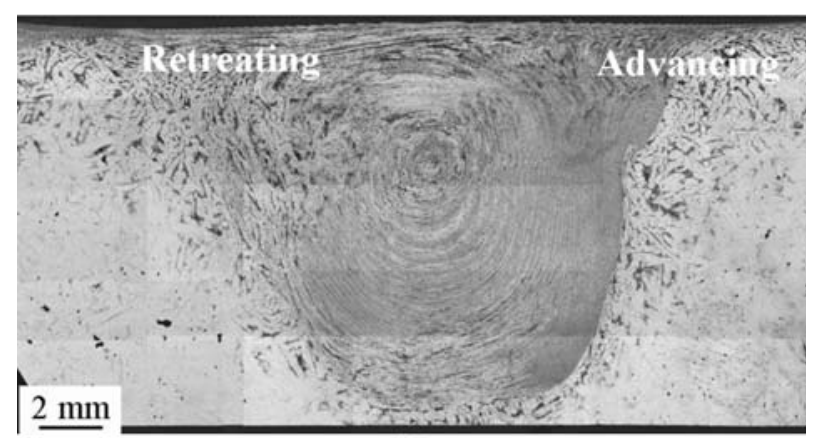

(b)

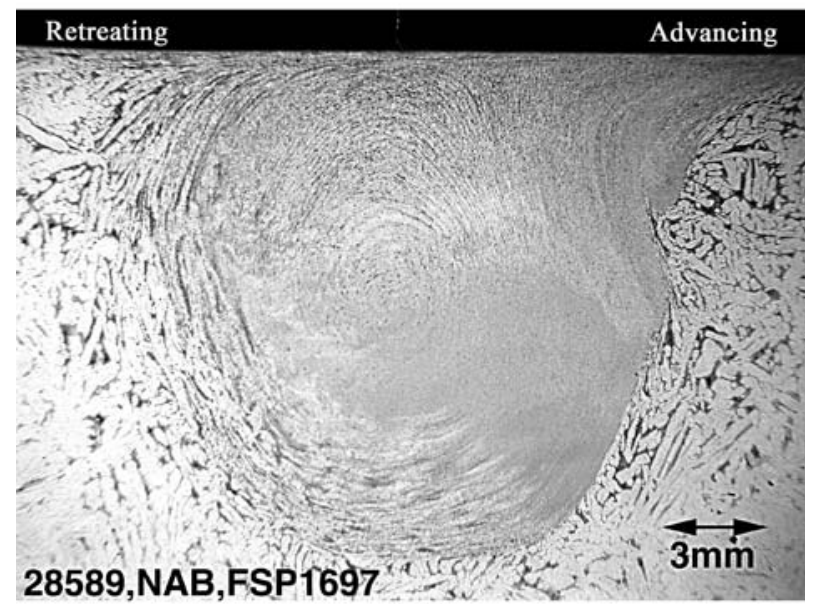

(c)

Fig. 4-Transverse cross-sectional views of the SZ, TMAZ, and base metal for NiAl bronze material processed at ambient temperature and (a) $1000 \mathrm{rpm}$ and $50.8 \mathrm{~mm} \mathrm{~min}^{-1}$, (b) $1000 \mathrm{rpm}$ and $152.4 \mathrm{~mm}$ $\min ^{-1}$, and (c) after preheating to $400{ }^{\circ} \mathrm{C}$ and processing at $1000 \mathrm{rpm}$ and $50.8 \mathrm{~mm} \mathrm{~min}^{-1}$.

interface between the $\mathrm{SZ}$ and the surrounding material is distinct, indicating a steep strain gradient on the advancing side of the tool. In contrast, the interface beneath and on the retreating side of the SZ is more diffuse, especially just under the surface in contact with the tool shoulder. In this region, the base metal appears to have been pulled into the SZ by the action of the tool shoulder after passage of the tool pin. The SZ is surrounded by material that appears to have been heated into the eutectoid temperature range but has experienced little or no plastic deformation. This region is termed the TMAZ and is delineated here again by the 


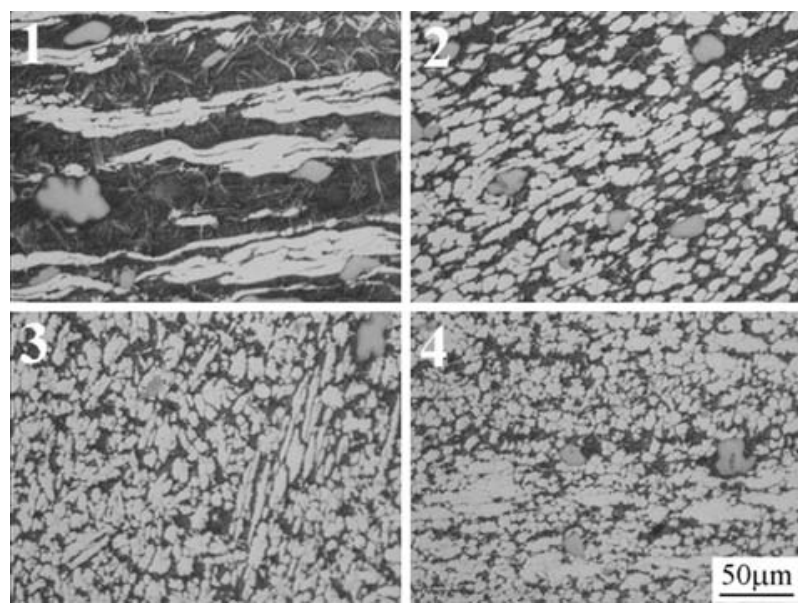

Fig. 5-Higher-magnification micrographs from locations denoted 1 through 4 in Fig. 4(a) for material processed at $1000 \mathrm{rpm}$ and $50.8 \mathrm{~mm} \mathrm{~min}^{-1}$.

dark-etching $\beta$-transformation products formed on cooling after reversion of the eutectoid constituent. The as-cast base metal microstructure beyond the TMAZ comprises the primary $\alpha$ and eutectoid $\alpha+\kappa_{\mathrm{iii}}$, although the lamellar morphology is not resolved at this low magnification. Details of the as-cast microstructure have been given in previous reports. ${ }^{[8,9,11-15,17-24]}$

Higher-magnification images from the regions denoted 1 through 4 in Figure 4(a) are shown in Figure 5. These images reflect a vertical traverse downward from the plate surface in contact with the tool along the centerline of the SZ for material processed at

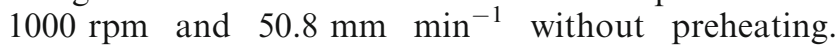
Region 1 exhibits bandlike features consisting of $\alpha$ grains (light etching) and $\beta$-transformation products (dark etching) that are elongated and aligned nearly perpendicular to the tool traversing direction in the transverse plane. Globular $\kappa_{\mathrm{ii}}$ particles are also apparent in this image. The primary $\alpha$ appears to have recrystallized, but the new grains also appear to have experienced further deformation, leading to a fragmented appearance of this constituent. The volume fraction of $\beta$-transformation products $V_{\beta}$ exceeds 0.5 in region 1 , and these products include fine Widmanstätten $\alpha$ and bainite, reflecting cooling at 2 to $3 \times 10^{1}{ }^{\circ} \mathrm{C} / \mathrm{s}$ (Table II), i.e., rates $\sim 10^{4}$ times that of the as-cast condition. In region 2 , the microstructure consists of nearly equal volume fractions of primary $\alpha$ and $\beta$-transformation products as well as globular $\kappa_{\text {ii }}$ particles. The directionality in this region reflects the onionring structure formed by the stirring action of the tool. The volume fraction of primary $\alpha$ increases upon traversing down the centerline of the SZ (regions 3 and 4). In these regions, very fine recrystallized and equiaxed primary $\alpha$ grains are apparent, although some grain elongation may still be discerned. Globular $\kappa_{\mathrm{ii}}$ particles are apparent throughout this SZ.

Plots of $V_{\beta}$ as a function of depth in the $\mathrm{SZ}$ are shown in Figure 6 for the materials processed without preheating. These data show that $V_{\beta}$ increases to a local

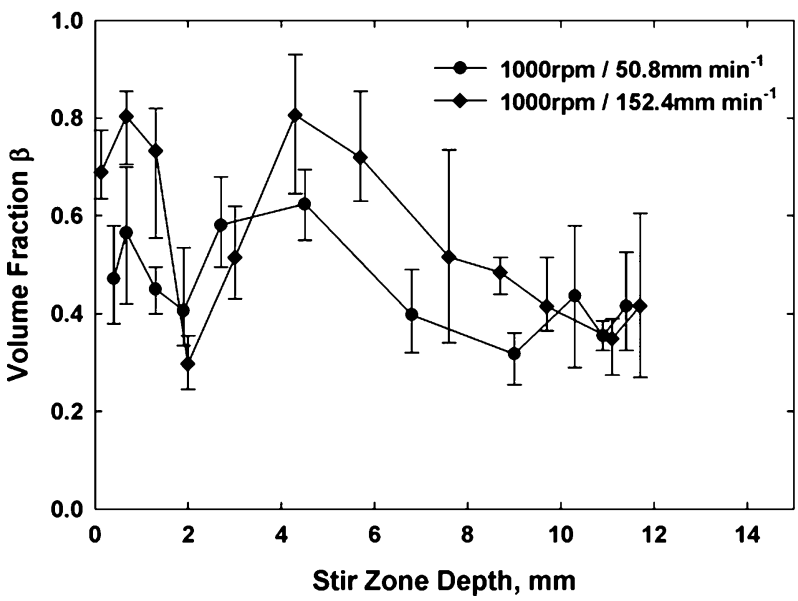

Fig. 6-Volume fraction of $\beta, V_{\beta}$, as a function of SZ depth for materials processed at $1000 \mathrm{pm}$ and either 50.8 or $152.4 \mathrm{~mm} \mathrm{~min}^{-1}$. Average values of $V_{\beta}$ as well as the range of values are plotted.

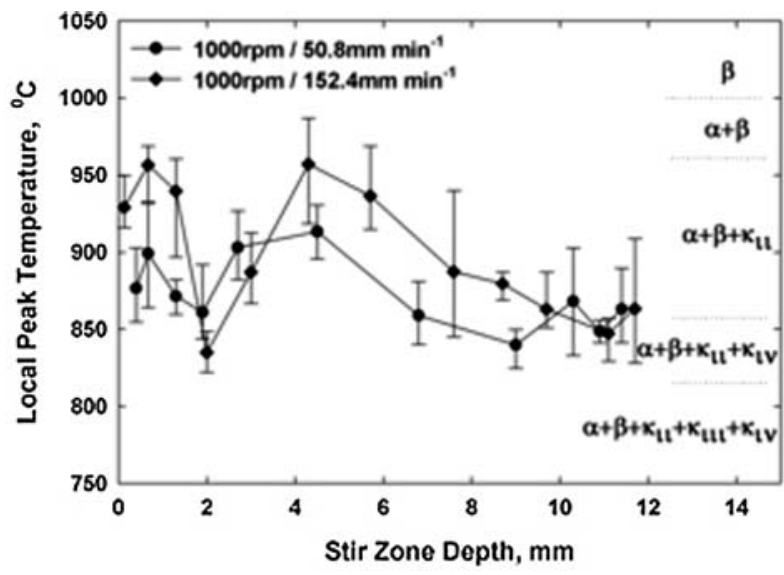

Fig. 7-Corresponding microstructure-based estimates of local peak temperature and range of peak-temperature values for the $V_{\beta} v s$ depth data of Fig. 6 are shown. These data indicate that the maximum temperature value is at a SZ depth of $\sim 4 \mathrm{~mm}$.

maximum approximately $1.0 \mathrm{~mm}$ below the plate surface, decreases to a local minimum at $2.0 \mathrm{~mm}$, and then increases to the overall maximum peak value at 4.2 to $4.3 \mathrm{~mm}$ before decreasing with depth to the bottom of the SZ. The local minimum at $\sim 2.0 \mathrm{~mm}$ corresponds roughly to the beginning of the onion-ring pattern. Corresponding local peak-temperature values were calculated using the approach given in Section II, and the results are presented in Figure 7 . The relationship between the $V_{\beta}$ and the temperature is linear and so the calculated temperature-depth relationship exhibits the same variation with depth as is observed in the $V_{\beta}$-depth plots. The highest peak-temperature values in the plots in Figure 7 are seen at SZ depths of 4.1 to $4.3 \mathrm{~mm}$. These values as well as interpolated values of peak temperatures at depths of $6.35 \mathrm{~mm}$ (the location of the thermocouple tips prior to FSP) are summarized in Table III along with peak-temperature data from Table II. 
Table III. Peak Temperatures Recorded by Different Techniques; Centerline Thermocouple Measurements Are Reported Here

\begin{tabular}{llll}
\hline Processing Conditions & \multicolumn{1}{c}{ Microstructure } & Thermocouple & Optical Pyrometry \\
\hline $1000 / 50.8$ & $920{ }^{\circ} \mathrm{C}(\sim 4.3 \mathrm{~mm})$ & $992{ }^{\circ} \mathrm{C}$ (centerline) & $944{ }^{\circ} \mathrm{C}($ surface $)$ \\
& $870{ }^{\circ} \mathrm{C}($ at $\sim 6.35 \mathrm{~mm})$ & $980{ }^{\circ} \mathrm{C}($ at $\sim 6.35 \mathrm{~mm})$ & $970{ }^{\circ} \mathrm{C}($ surface $)$ \\
$1000 / 152.4$ & $960^{\circ} \mathrm{C}(\sim 4.1 \mathrm{~mm})$ & & \\
\hline
\end{tabular}

\section{DISCUSSION}

Peak SZ temperatures have been evaluated by means of thermocouples embedded in the tool path, optical pyrometer measurements of the surface temperature at the tool heel, and quantitative analysis of microstructure constituents reflecting FSP-induced phase changes. Altogether, the peak SZ temperatures obtained by these independent measurement techniques are in close agreement (Table III) and demonstrate that SZ peak temperatures are 0.90 to $0.97 T_{\text {Melt }}$ during the FSP of this $\mathrm{NiAl}$ bronze material.

The thermal cycles depicted in Figures 2(a), (c), and (e) are suggestive of the analytical solution obtained by Rosenthal ${ }^{31]}$ for three-dimensional heat flow in a semiinfinite workpiece during welding. The Rosenthal equation assumes a moving-point source of heat at the origin of a moving reference frame and considers heat flow only by conduction. Modifications of the solution include assumption of a distributed heat source to avoid a singularity at the origin. Nevertheless, the rapid heating and slower cooling responses observed in the thermocouple data are consistent with the original analytical formulation. Furthermore, the form of the complete thermal cycle for locations at the edge or outside of the SZ, e.g., the retreating side thermocouples, with rapid heating to the peak temperature and slower cooling after passage of the heat source, is implicit in the Rosenthal equation.

The cooling rates at the back edge of the SZ along the traversing axis behind the tool where deformation has just ceased may be estimated from ${ }^{[31,32]}$

$$
\left.\frac{\partial T}{\partial t}\right|_{x}=-2 \pi k \frac{\left(T-T_{0}\right)^{2}}{(Q / U)}
$$

where $T$ is the temperature, $t$ is the time, $k$ is the workpiece thermal conductivity $(\mathrm{J} / \mathrm{msK}), T_{0}$ is the initial (preheating) temperature, $Q$ is the power dissipated by the heat source (W), and $U$ is the traversing speed of the heat source $(\mathrm{m} / \mathrm{s})$. In the usual derivation of Eq. [1], $T \sim T_{\text {Melt }}$ is assumed and cooling rates at the edge of the liquid weld metal behind the heat source may then be estimated. Here, the temperature $T \sim 800{ }^{\circ} \mathrm{C}$ at the SZ/TMAZ interface (e.g., Figure 4). If this value is used in place of $T_{\text {Melt }}$ in Eq. [1], the effects of the traversing rate and preheating temperature $T_{0}$ on the heating and cooling rates may be assessed. If $Q$ is assumed constant for processing at $1000 \mathrm{rpm}$, then increasing the traversing rate from 50.8 to $152.4 \mathrm{~mm} \mathrm{~min}^{-1}$ should increase cooling rates by a factor of 3 . Indeed, a comparison of the advancing side, centerline, and retreating side cooling rates at $800{ }^{\circ} \mathrm{C}$ in Table II reveals ratios of 2.9 to 3.2 for these locations. Likewise, increasing the preheating temperature from $25^{\circ} \mathrm{C}$ to $400{ }^{\circ} \mathrm{C}$ would reduce the advancing side, centerline, and retreating side cooling rates by a factor of 3.75, according to Eq. [1]. Corresponding ratios for traversing at a rate of $50.8 \mathrm{~mm}$ $\min ^{-1}$ in the data of Table II are 6.0 for the advancing side, and 4.7 and 2.9 for the centerline and retreating sides, respectively. The advancing side thermocouple remained on the advancing side in preheated material while being displaced to the retreating side in the material that was not preheated. Thus, the advancing side thermocouples in materials processed at $50.8 \mathrm{~mm}$ $\min ^{-1}$ have experienced different histories depending on the initial plate temperatures. Altogether, Eq. [1] correctly predicts trends in the effects of the traversing rate and preheating on the cooling rates, but improved accuracy would require a detailed understanding of the plastic flow within the SZ.

The thermocouple placement was intended to enable assessment of the variation in the SZ peak temperatures from the advancing to the retreating side. Examination of the thermocouple data in Table II suggests that the peak temperatures are higher on the advancing side than on the retreating side by $9{ }^{\circ} \mathrm{C}$ to $23{ }^{\circ} \mathrm{C}$. The centerline peak temperatures are intermediate for materials processed without preheating, while the centerline peak temperature is the highest temperature recorded in preheated material. However, the advancing and centerline temperature profiles in Figures 2(b), (d), and (f) also suggest that the thermocouples have begun to move prior to the temperature attaining a maximum value. This is reflected in the rapid temperature fluctuations along these profiles as the thermocouple tips were being displaced by the approaching tool, and direct microscopy also showed extensive displacement of thermocouples in these positions. Heat generation by direct contact between the tool and the thermocouple sheath may also be a factor in the temperature profiles for the advancing and centerline thermocouples.

Microstructure-based analysis of the peak-temperature distribution across the SZ has been reported previously for this same NiAl bronze material subjected to a single FSP pass at $1000 \mathrm{rpm}$ and $101.6 \mathrm{~mm} \mathrm{~min}^{-1}$, ${ }^{11]}$ i.e., a traversing rate intermediate to those of the present investigation. The data were obtained along five vertical traverses at up to nine locations along each traverse. The traverses are denoted as R1, R2, C3, A4, and A5, as illustrated in Figure 8(a). A single point count was conducted at each location and the resulting data are replotted here in Figure 8(b) as the peak temperature as a function of the depth along each traverse. These data 


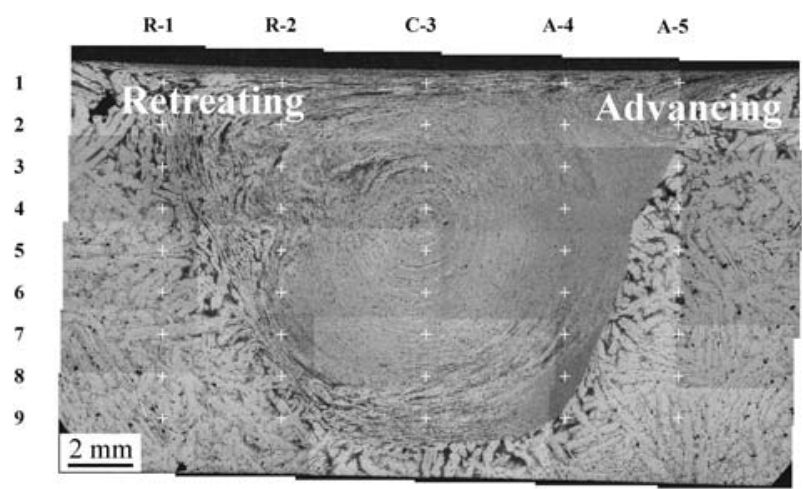

(a)

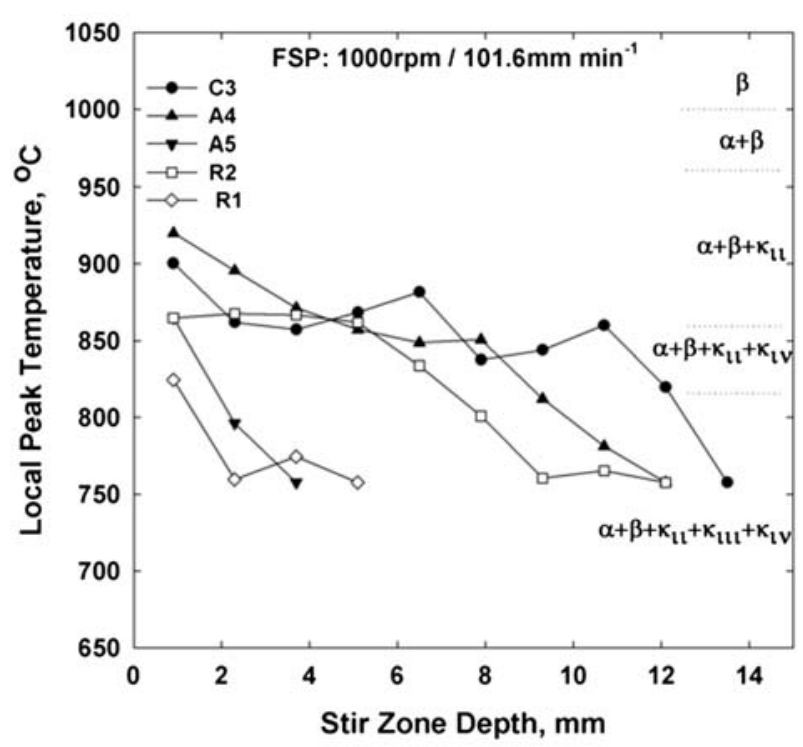

(b)

Fig. 8-(a) Transverse view of the SZ, TMAZ, and base metal microstructures for material processed at $1000 \mathrm{rpm}$ and an intermediate traversing rate of $101.6 \mathrm{~mm} \mathrm{~min}^{-1}$. (b) Microstructure-based estimates of local peak temperature as a function of SZ depth for five different downward traverses through the SZ. These data suggest that advancing and retreating sides exhibit similar temperature-depth profiles.

suggest that the peak temperature is highest on the advancing side at an SZ depth of $1 \mathrm{~mm}$, i.e., immediately below the surface in contact with the tool, while the retreating side temperature appears slightly higher at approximately $6.5 \mathrm{~mm}$, i.e., the SZ mid-depth. However, temperature differences across the SZ are within the likely error in the estimated temperature measurement (e.g., Figure 7). Thus, an unambiguous conclusion regarding temperature variation across the $\mathrm{SZ}$ cannot be drawn from these data. This is consistent with the results of the present study, in which displacements of the advancing and centerline thermocouples at temperatures near the peak value preclude an unambiguous assessment of the peak-temperature variation across the SZ.

The microstructure-based estimates indicate that the highest SZ temperatures are found just below the tool shoulder, reflecting frictional and adiabatic heating effects associated with the shoulder as well as the pin.
The peak-temperature estimation deeper inside the SZ is complicated by the tool features that induce complex displacements of material vertically as well as around the pin. Thus, material at any location in the SZ after processing likely was not at that same location prior to passage of the tool. A more complete description of the SZ temperature history will require a detailed understanding of the SZ strain history, as well.

Finally, in Table III, the microstructure-based estimates and optical pyrometry measurements suggest that the SZ peak temperatures increase somewhat as the tool traversing rate increases. In contrast, the thermocouple data indicate that the SZ peak temperature decreases slightly with the increasing tool traversing rate. Heating during FSP is due to frictional and adiabatic effects as the tool rotates and advances relative to the workpiece. At $1000 \mathrm{rpm}$, the surface speed of the tool at the base of the pin under the shoulder is $\sim 4.7 \times 10^{4} \mathrm{~mm} \mathrm{~min}^{-1}$ relative to the workpiece surface, so that tool translation rates in the present work ( 50.8 to $152.4 \mathrm{~mm} \mathrm{~min}^{-1}$ ) will have a negligible effect on the tool surface speed. Nevertheless, traversing of the tool clearly affects the flow about the tool pin and leads to the asymmetry of deformation from the advancing to the retreating size of the SZ, which is apparent in Figure 4. It is also possible that increased traversing rates result in foreshortening of the SZ ahead of the tool, increasing local strain rates and, thus, adiabatic dissipation, giving a concomitant increase in the local temperature. Again, a complete interpretation of the temperature distribution requires an improved understanding of the SZ strain history.

\section{CONCLUSIONS}

The following conclusions may be drawn from this investigation of the SZ thermal cycle by embedded thermocouples as well as by measurements using optical pyrometer and microstructure-based estimates of the peak SZ temperature.

1. The SZ thermal cycles can be measured by means of embedded thermocouples placed directly in the tool path. Such thermocouples will be displaced and so the thermal cycle will reflect the temperature along a path through the SZ and not the temperature at a specific location.

2. Peak SZ temperatures are 0.92 to $0.97 T_{\text {Melt }}$, as measured by thermocouples embedded in the tool path, and have at most a small dependence on the tool traversing rate and preheating temperature for the range of values employed in the present investigation.

3. Preheating to $400{ }^{\circ} \mathrm{C}$ retards heating as well as cooling rates and increases the dwell time at temperature during the FSP-induced thermal cycle.

4. Analytical solutions based on Rosenthal's equation for the cooling rate along the traversing axis behind a moving-point heat source predict trends in the dependence of the cooling rate at $800{ }^{\circ} \mathrm{C}$ (i.e., the SZ/TMAZ interface temperature) on the tool traversing rate. 
5. Pyrometer measurements of the surface temperature at the tool heel are $0.92 T_{\text {Melt }}$ for a tool traversing rate of $50.8 \mathrm{~mm} \mathrm{~min} \mathrm{~mm}^{-1}$ and are independent of the preheating temperature, and $0.94 T_{\text {Melt }}$ for a traversing rate of $152.4 \mathrm{~mm} \mathrm{~min}^{-1}$.

6. Microstructure-based estimates suggest slightly lower local peak SZ temperatures (as low as $\sim 0.9 T_{\text {Melt }}$ ) when compared to embedded thermocouple and pyrometer measurements for the material processed at $50.8 \mathrm{~mm} \mathrm{~min} \mathrm{mith}^{-1}$ without preheating. Such estimates for the material processed at $152.4 \mathrm{~mm} \mathrm{~min}^{-1}$ without preheating are consistent with thermocouple and pyrometer measurements.

7. Interpretation of the peak-temperature variation from the advancing to the retreating side of the SZ is made difficult because of advancing and centerline thermocouple displacements and possible thermocouple contact with the tool pin. Corresponding peak-temperature variations from microstructure-based estimates are generally within the measurement error.

\section{ACKNOWLEDGMENTS}

The authors acknowledge prior support and funding for this work from the Defense Advanced Projects Agency (DARPA) (Arlington, VA), with Dr. Leo Christodoulou as program sponsor, and current support from the Office of Naval Research (ONR) (Arlington, VA), under Contract Nos. N00014-06WR-2-0196 and N00014-09-WR20201, with Drs. Julie Christodoulou, John Deloach, and Richard Fonda as program sponsors.

\section{REFERENCES}

1. W.M. Thomas, E.D. Nicholas, J.C. Needham, M.G. Murch, P. Templesmith, and C.J. Dawes: Great Britain Patent Application 9125978.8, Dec. 1991; U.S. Patent 5460317, Oct. 1995.

2. R.S. Mishra: Adv. Mater. Processes, 2003, vol. 161, pp. 43-46.

3. R.S. Mishra, Z.Y. Ma, and I. Charit: Mater. Sci. Eng., A, 2003, vol. 341 , pp. $307-10$.

4. T.J. Lienert, W.L. Stellwag, Jr., B.B. Grimmett, and R.W. Warke: Weld. J., 2003, vol. 82, pp. 1S-9S.

5. L. Cui, H. Fujii, N. Tsuji, and K. Nogi: Scripta Mater., 2007, vol. 56, pp. 637-40.

6. G. Buffa, J. Hua, R. Shivpuri, and L. Fratini: Mater. Sci. Eng., A, 2006, vol. 419, pp. 389-96.
7. P. Vilaca, L. Quintino, J.F. dos Santos, R. Zettler, and S. Sheikhi: Mater. Sci. Eng., A, 2007, vols. 445-446, pp. 501-08.

8. K. Oh-Ishi and T.R. MeNelley: Metall. Mater. Trans. A, 2004, vol. 35A, pp. 2951-61.

9. K. Oh-Ishi and T.R. McNelley: Metall. Mater. Trans. A, 2005, vol. 36A, pp. 1575-85.

10. K. Oh-Ishi, A.P. Zhilyaev, and T.R. McNelley: Metall. Mater. Trans. A, 2006, vol. 37A, pp. 2239-51.

11. T.R. McNelley, K. Oh-Ishi, and A.P. Zhilyaev: in Friction Stir Welding and Processing, R.S. Mishra and M.W. Mahoney, eds., ASM INTERNATIONAL, Materials Park, OH, 2007, pp. 15573.

12. E.A. Culpan and G. Rose: Br. Corros. J., 1979, vol. 14, pp. 16066.

13. G.M. Weston: Survey of Nickel-Aluminum Bronze Casting Alloys for Marine Applications: Australia Department of Defence Report DSTO MRL-R807, Australia Department of Defence, Melbourne, Australia, 1981, pp. 1-38.

14. P. Brezina: Int. Met. Rev., 1982, vol. 27, pp. 77-120.

15. E.A. Culpan and G. Rose: J. Mater. Sci., 1978, vol. 13, pp. 164757.

16. G.W. Lorimer, F. Hasan, J. Iqbal, and N. Ridley: Br. Corros. J., 1986, vol. 21, pp. 244-48.

17. D.M. Lloyd, G.W. Lorimer, and N. Ridley: Met. Technol., 1980, vol. 7, pp. 114-19.

18. F. Hasan, G.W. Lorimer, and N. Ridley: Proc. Int. Conf. on Solidto-Solid Phase Transformations, TMS, Warrendale, PA, 1982, pp. 745-49.

19. F. Hasan, A. Jahanafrooz, G.W. Lorimer, and N. Ridley: Metall. Trans. A, 1982, vol. 13A, pp. 1337-45.

20. F. Hasan, G.W. Lorimer, and N. Ridley: J. Phys., 1982, vol. 43, pp. C4653-C4658.

21. A. Jahanafrooz, F. Hasan, G.W. Lorimer, and N. Ridley: Metall. Trans. A, 1983, vol. 14A, pp. 1951-56.

22. F. Hasan, G.W. Lorimer, and N. Ridley: Met. Sci., 1983, vol. 17, pp. 289-95.

23. F. Hasan, J. Iqbal, and N. Ridley: Mater. Sci. Technol., 1985, vol. 1 , pp. $312-15$

24. P. Weill-Couly and D. Arnaud: Fonderie, 1973, No. 322, pp. $123-$ 35 .

25. J.L. Robbins, O.C. Shepard, and O.D. Sherby: J. Iron Steel Inst., 1964, vol. 202, pp. 804-07.

26. O.D. Sherby, B. Walser, C.M. Young, and E.M. Cady: Scripta Metall., 1975, vol. 9, pp. 569-73.

27. B. Walser and O.D. Sherby: Metall. Trans. A, 1979, vol. 10A, pp. $1461-71$

28. Metals Handbook: Properties and Selection of Nonferrous Metals and Special Purpose Materials, 10th ed., A. Cohen, ed., ASM INTERNATIONAL, Metals Park, OH, 1990, vol. 2, pp. 386-87.

29. Y. Rabin and D. Rittel: Exp. Mech., 1999, vol. 39 (2), pp. 132-36.

30. K.M. Garrity, D.C. Ripple, M. Araya, C.R. Cabrera, L. Cordova Murillo, M.E. de Vanegas, D.J. Gee, E. Guillén, S. MartinezMartinez, E. Mendez-Lango, L. Mussio, S.G. Petkovic, K.N. Quelhas, G. Rangugni, O. Robatto, and E. von Borries Rocha: Int. J Thermophys., 2008, vol. 29, pp. 1828-37.

31. D. Rosenthal: Weld. J., 1941, vol. 20, pp. 220s-234s.

32. S. Kou: Welding Metallurgy, 2nd ed., J. Wiley, Hoboken, NJ, 2003, pp. 47-58. 